\title{
The Interplay of Alcohol and Wellbeing in the Workplace: Combining Soft Systems Methodology and Foucauldian Approach
}

\author{
Samuel Osei-Nimo ${ }^{1}$ (D) Cindy Millman ${ }^{1}$ (D) Emmanuel Aboagye-Nimo ${ }^{2}$
}

Accepted: 3 February 2022 / Published online: 19 February 2022

(c) The Author(s) 2022

\begin{abstract}
This paper focuses on the topic of alcohol and wellbeing in contemporary work organisations. It explores the relationship between stakeholders' viewpoints regarding alcohol in the workplace and how they have shaped organisational practices regarding wellbeing. The work of Michel Foucault is used to explore these issues. The notions of power, knowledge and discipline are identified as key Foucauldian themes that offer an alternative understanding of how discourses on alcohol are shaped in the United Kingdom workplace. The paper combines certain stages of Checkland's Soft Systems Methodology and Foucault's Poststructuralist approach in addressing the topic. Foucault's method of analysis, particularly archaeology and genealogy, is used to explore how and why certain discourses surrounding alcohol in the workplace become dominant over time. Qualitative cases with semi-structured interviews in knowledge-intensive firms were adopted to capture contrasting, varied experiences and perceptions of these organisational actors and shed light on alcohol and wellbeing and its relationships with the power dimension.
\end{abstract}

Keywords Alcohol · Wellbeing $\cdot$ Soft Systems Methodology $\cdot$ Power $\cdot$ Foucault

\section{Introduction}

Research about alcohol in the workplace is an ever-growing field (Roche et al. 2020), with inferences often drawn between employees' wellbeing, health and safety (H\&S) and alcohol use (Ghodse 2016; Roche 2017). Alcohol and drug misuse present a multifaceted and problematic challenge that destroys vast individual lives and undermines British society's H\&S (Cumberledge cited Ghodse 2016). However, Nesvåg and Duckert (2017) argued that drinking alcohol can be a source of enjoyment and relaxation. Sullivan et al. (2019) supported this, stating that alcohol consumption is legal and enjoyed moderately and

Samuel Osei-Nimo

samuel.osei-nimo@bcu.ac.uk

1 Department of Strategy, Management and Marketing, Birmingham City University, 15

Bartholomew Row, Birmingham B5 5JU, UK

2 University of Brighton, Cockcroft Building, Lewes Road, Brighton BN2 4GJ, UK 
reasonably by most adults in many circumstances, including at or around the workplace. It also has utility influencing organisational identity formation and reflects social norms (Walker and Bridgman 2013).

Businesses are increasingly aware of the importance of worker's H\&S and wellbeing for organisational functioning (Roche et al. 2019). For example, alcohol and drug use has been associated with injuries, decreased productivity, absenteeism/presenteeism, and antisocial behaviour (De Graff et al. 2012; French et al. 2011). Roche et al. (2017) argued that factors such as culture, policies, and the physical environment of a workplace could enhance worker safety and productivity (Frone 2015) or contribute to poor health and trigger higher stress and substance use rates (Mackey and Perrewé 2017). Most workplace alcohol analyses have traditionally employed 'managerial and hierarchical' approaches, focusing on experts/managers' viewpoints and overlooking/excluding other stakeholders (in this context, lower-tiered employees). Various initiatives and training programmes at the workplace were developed to reduce alcohol consumption (CIPD 2020; Ghodse 2016; TUC 2019). However, the relationships between stakeholders' viewpoints and how these have subsequently shaped organisational practices of wellbeing remain under-explored.

This study aims to address this gap and explores insights from various stakeholders about alcohol and wellbeing in the United Kingdom (UK) knowledge-intensive workplaces. According to a recent study by PwC (2021), the business services sector, under which Knowledge-Intensive firms fall, continues to experience strong growth and now employs over six million people and is a significant contributor to UK productivity growth. The three cases selected for this research are defined as 'Knowledge-Intensive' because they all share characteristics with a growing list of professional service organisations that heavily rely on individual and collective forms of intellectual capital (Robertson and Swan 2004). Individuals employed in such 'white-collar' occupations are under-represented in alcohol research and often consider their alcohol use positive and within personal control (Ling et al. 2012; Muhlack et al. 2018). We consider sampling from this sector is critical in understanding the issue of alcohol as it represents a key area of concern for the UK government and broader social discourse on the topic (Burton et al. 2016; Public Health England 2018). We recognise that although this paper might not be statistically representative, the discourses gathered would contribute to the general reflections at the national level.

We used Foucault's method of analysis, namely, archaeological and genealogical stages, to shed light on alcohol and wellbeing at the workplace. The former focuses on exploring social artefacts gathered by the study of interviews, texts, perceptions, and points of view, among other things. The latter examines how these interplays give what is considered as 'common sense' or 'prevailing view' at a particular moment. However, Foucault did not provide a particular means or method of approaching this phase but only highlighted that the vital aim is to gather discourses and statements without passing judgment or proving the veracity of one over the other. We used Checkland's Soft Systems Methodology (SSM) to address this method 'omission'. However, unlike most traditional research on alcohol in the workplace (CIPD 2020; TUC 2019), this paper is not intended to provide an absolute answer to the issue of alcohol in the workplace but rather to contribute to a greater understanding of the actual workplace practices linked to the use of alcohol. It is not surprising that Foucault's approach attracts some criticism. A poststructuralist perspective, according to Rosenau (1992: 143), appears to "engender a cynical, nihilistic, and pessimistic political tone". From a policymakers viewpoint, Parker (1992: 24) adds that such an approach is perceived as endorsing a relativistic form of political impotence where "instead of trying to change the world, the point is merely to reinterpret it". Similar critiques have been levelled against SSM for being politically neutral (Thomas and Lockett 1979). 
SSM was devised to shape interventions in the problematic situations met in management, organisational and policy contexts, where clear-cut 'problems' or straightforward 'solutions' are hardly present. We used particular stages of SSM in identifying and organising the different views and opinions of stakeholders involved in the debate while sticking to Foucault's recommendation of not judging or trying to prove the veracity of one discourse over the other. In line with this, the genealogical method of analysis offered a way of studying power relations without rejecting the archaeological dimension, which provides the material for it (Välikangas and Seeck 2011; Raffnsøe et al. 2016; Stowell 2020). By combining SSM and Foucault's method of analysis, this paper attempts to address the following research questions: (a) What are the relationships between various stakeholders' viewpoints toward alcohol use, and how do these shape organisational identities and practices in wellbeing? (b) Can certain stages of Checkland's SSM contribute to understanding Foucault's Poststructuralist approach in analysing alcohol in the workplace? If so, to what extent?

The paper is organised as follows. First, it examines the literature on alcohol and wellbeing at the workplace to frame its theoretical focus. Second, it outlines the foundations of the genealogical approach adopted, arguing that a Foucauldian analysis of alcohol offers a unique way of examining power relations. The question of power and knowledge and the mechanisms through which discursive powers work on individual bodies in the workplace could be examined. Third, the organisational context and research methodology were outlined, followed by data analysis, using SSM stages and Foucault's genealogical method. Conclusion and contributions were highlighted.

We argue that power and knowledge dynamics significantly shape the discourses and debate around alcohol in the UK workplace, mainly with organisational practices and identities relating to wellbeing of the workforce (Stowell 2020). This contributes to sustaining the normalisation of ensuing practices and identities around the substance in the workplace. We contend that the discourses and practices relating to alcohol make it possible to regulate individuals and define, with the support of scientific disciplines and 'expert' knowledge, their bodies and workplace behaviours (Yu and Hong 2009). Thus, the inclusion of different views and perceptions of alcohol in the discussion in the workplace indeed represent a significant contribution of this research. Our approach ensures that the prevailing discourses of adverse drinking outcomes do not crowd out the competing views that contribute to shaping how alcohol is perceived in the UK workplace.

\section{Alcohol, employment and work culture in the UK}

In a seminal study commissioned by the British Medical Association (BMA) Occupational Medicine Committee to investigate the risks of alcohol in the UK workplace, Nicholson et al. (2017) maintained that there is evidence to support the claim that individuals in employment are more likely to consume alcohol regularly than unemployed people. They identified that individuals in managerial and professional occupations are likely to drink more frequently than ones in routine and manual jobs. Particularly in the UK, Galea and Ghodse (2016) add that some working situations and conditions include remote working, business dinners, shift and night work, exacerbate the issue of alcohol (Lucas 2016). Alcohol use in the workplace has long been perceived as being associated with accidents, inefficiency, presenteeism and absenteeism (Gill 1994; Bhattacharya 2019). Woodhouse (2020) highlighted that alcohol use in the workplace invariably has detrimental effects on 
employees' health and social behaviour. However, most studies related to alcohol and wellbeing in the UK workplace focuses more on blue-collar jobs in safety-critical industries than professional white-collar jobs (Godfrey and Parrot 2016).

Moreover, the contention over the definition of alcohol misuse or abuse remains. Banta and Tennant (1989) made two observations on the definition issue: Firstly, in relation to wellbeing, there is a debate over defining alcoholism and its causes as an illness, whilst most definitions agree that it is a condition of dependency. Secondly, alcohol is, of course, a drug, and suggestions have been made that efforts employed in addressing alcohol in the workplace should be similar to those employed against illicit drug use (Frone 2015; Thompson et al. 2017). Henderson et al. (1996) emphasise the importance of identifying the interaction between general drinking levels and specific working conditions. They argue that the connection between intake and the nature of work performed by the workers is critical in sustaining drinking cultures. Nonetheless, unless an understanding or evaluating the premise of these 'problems' is well developed, modern organisations might critically miss the vital issue of workplace culture (Ames and Grube 1999).

Allsop and Pidd (2001) highlight workplace culture as the central factor to consider when shaping workplace expectations and the social environment regarding the use of 'legal' drugs such as alcohol and illicit drugs. For instance, they specified that:

In a variety of cultures, formal and informal pressures encourage weekly after-work team building and relaxation based on alcohol consumption. Sanctioned drugs such as caffeine and tobacco have been embraced in ritualised breaks in worktime (Allsop and Pidd 2001, p. 5).

Midford (2001) reviewed workforce alcohol consumption and concluded that the alcohol consumption level among white and blue-collar jobs was on a par. Nonetheless, Ling et al. (2012) argue that few studies have investigated how alcohol is perceived by this relatively unconsulted segment of the population: white collar workers.

Ames and Grube (1999) highlight lack of control, work stress and alienation linked with the individuals' perceptions of powerlessness are essential contributors to substance misuse in most workplaces. Galea and Ghodse (2016) argue that the work environment and alcohol discussion is shaped by employee characteristics, organisational attitudes, and societal beliefs and trends. These individuals play a huge role in shaping the acceptance or rejection of workplace culture, encouraging or discouraging a work environment that potentially has alcohol-related problems.

\section{The Notion of Wellbeing and Self-surveillance}

Watson (2017) suggests, in the analysis of any aspect of human existence, mainly where work institutions are concerned, there is always a fundamental need to address the interplay between the patterns or shaping of the social life and the diverse interests of the individuals who produce and function inside such structuring. The idea of wellbeing is a popular notion of contemporary society that has also signified rising attention to individual wellbeing present in a social context, which emphasises proactive agency and self-responsibility as significant and normal, with the self and the body providing particularly amenable arenas for the exercise of a self-responsible agency (Rose 1990, 1999; Sointu 2005). It could be considered that the growing discussion about 'wellbeing' could be attributed to 
the shifts in the nature of subjectivity and specifically to the rise of the dynamic individual as the driving force in the construction of individual wellbeing.

Sointu (2005) points out that the kind of self-responsible individual seeking personal wellbeing can be understood as a subject that has emerged through changes in appropriate selfhood perceptions. In this instance, Taylor (1994) accused 'modernity' of providing a channel through which "unique truths were to be reflected on and discovered" through the individual self (Sointu 2005, p. 261). Sointu explains, the individual was assumed to have manoeuvered through the 'subjective turn' and thus regarded as possessing inner depth and being discernible and fully human simply through exhibiting the capacities of self-reflection. Besides, he or she could locate truth within an act that imposed self-reflection and 'objectification' as virtues that were viewed to be ethically and morally right.

By situating the issue of the individual's wellbeing and health, Rumsby (2009, p. 30) generally defines wellbeing as:

“... an active, culturally mediated, temporally fluctuating, bio-psychosocial state of an individual or group, associated with meaningfulness and purpose in life. It comprises eudaimonic (self-determining), personal resources and capabilities for human flourishing, such as relatedness to others, positive emotions and resilience, and selfacceptance. Practical judgement involving values, experience and intuition guides and synthesises these resources dynamically".

Christopher (1999) argues that Western notions of psychological wellbeing may be profoundly shaped by their cultures' individualistic moral ideologies. The use of the term 'individualism' was referring to Foucault's (1984/1986, p. 42) caution and argued that the term is so often used with "entirely different concepts have been lumped together" and individualism "combines ontological claims about the nature of the self with normative prescriptions about the good or ideal person" (Foucault 1984/1986, p. 142). This mirrors Geertz' (1983, p. 59) conception in the western context:

"The Western conception of the person as a bounded, unique, more or less integrated motivational and cognitive universe, a dynamic centre of awareness, emotion, judgment and action organised into a distinctive whole and set contrastively against other such wholes and against its social and natural background, is, however incorrigible it may be to us, a rather peculiar idea within the context of world's cultures".

However, George and Hamilton (2010) argued that the current emergence and focus on wellbeing in contemporary societies and particularly its organisations had been attributed to the changing nature of the workplace and the surfacing of other social phenomena. Despite it being a debatable issue, the notion of wellbeing has its basis rooted historically and contemporaneously in different cultural contexts. Rumsby (2009) argues that although diverse conceptions may be present in different cultures, the same broad concept is seen to exist universally and that both accounts, either one rooted in eudaimonic or hedonic traditions, recognise those cultural traditions, socially constructed, maintained and constantly adapted affect how socially-available ideas are interpreted.

Deetz (1998) relates the notion of the self to wellbeing by drawing on Foucault's (1988) study on technologies of self-understanding that are present in the power games of truth and elaborates that the 'technologies of the self' are the most central to domination and control in the workplace. Foucault (1988, p. 18) proposed four techniques of self-understanding with each relating to a certain type of self-domination: (1) technologies of production, which permit us to produce, transform and manipulate thing; (2) technologies of sign systems, which permit us to use signs, meaning, symbols, or signification; (3) technologies of power, which 
determine the conduct of individuals and submit them to certain ends of domination, an objectivising of the subject; and (4) technologies of the self, which permit individuals to effect by their own means or with the help of others a certain number of operations on their own bodies and souls and thoughts, conduct, and way of being, to transform themselves to attain a certain state of happiness, purity, wisdom, perfection, or immortality.

Vaz and Bruno (2003) suggest that much discussion concerning new technologies of surveillance places heavy emphasis on Foucault's theoretical conception of the 'panopticon'. However, "other theoretical propositions of Foucault's are helpful in the study of new practices and technologies" of any form of surveillance (Vaz and Bruno 2003, p. 272). New studies of surveillance often over-emphasise the Panopticon and technological features in explaining the historical shifts and emphasise the surveillance of 'them' upon 'us'. It has been suggested that it is possible to relate it to Foucault's (1982) notion of power which cannot be located; instead, it is everywhere and can also be situated inside us (Vaz and Bruno 2003). This mirrors Rose's (1999) view which elaborates that power relations tend to produce the subject or, to be more specific, such relations inculcate in the individual a historically instituted relation with ones' self. Consequently:

“.... any practice of surveillance entails self-surveillance as its historical counterpart and it is this simultaneity that accounts for the acceptance and legitimisation of power relations...Self-surveillance is usually understood as the attention one pays to one's behaviour when facing the actuality or virtuality of an immediate or mediated observation by others whose opinion he or she deems as relevant - usually, observers of the same or superior social position" (Vaz and Bruno 2003, p. 273).

Hence by expanding the idea of self-surveillance, one can associate it with practices of the care of the self and effectively wellbeing. Practices of the self typically relate to the condition of the aspect of the individual which should be cared for and attended to, a shift that can be linked to the production of an ethical substance (Foucault 1985). In this regard, Vaz and Bruno (2003) argue that self-surveillance is founded on the cultural premise that particular thoughts and actions are unsafe or harmful to the constitution of the individual as a subject.

In a knowledge-intensive organisation context, Deetz (1998) cites that advanced levels of control exist whereby employees and managers, as employees, instrumentalise and strategise themselves. That is, via self-surveillance and controls of their bodies, beliefs, dress, conduct and behaviour, individuals "use themselves for their own strategised employment and careers movements" (Deetz 1998, p. 164). Hence, through self-management and surveillance practices, individuals in the workplace have strategised their subordination, thus rendered themselves collaborators in their exploitation (Burawoy 1985). This self-management is the "management of the inner world along normative lines through the use of self and professional knowledge" (Deetz 1998, p. 164). Thus such strategised subordination occurs as individuals in the organisation vigorously subordinate themselves to seek capital, security, meaning or identity (Knights 2002). Hence, self-surveillance is an aspect of the necessary care of the self, in the form of an attempt to constitute one's self as a normal citizen (Vaz and Bruno 2003).

\section{Research Methodology}

To address the research questions, we adopted a purposive sampling strategy to select information-rich cases over statistically representative ones that would result from probability sampling (Patton 2002). It draws on selecting interviews conducted with individuals 
working in three Multi-National Corporations (MNC) in the UK. Given its importance in the UK economy, the three organisations selected were business service firms as outlined previously. This industry represents a significant growth area in the UK and therefore is relevant to consider when addressing any issues concerning the contemporary British workplace (Duquemin et al. 2019). This choice ensured that the situation was thoroughly examined from various perspectives. It was to gather discourses among employees, which are often being overlooked in most mainstream/'managerialist' workplace-based studies. Hence, purposive sampling was appropriate and enabled us to illuminate the topic at hand (Suri 2011).

Semi-structured interviews were employed to provide qualitative information and facilitate a richer and in-depth understanding of the individuals' representations and experiences regarding alcohol and approaches to alcohol in their respective workplaces (McQueen et al. 2017). On a practical level, the selection of particular departments was motivated by their proximity and willingness to participate in this research. It also allowed a substantial degree of access to their respective organisations. We ensured that there is a balanced number of participants across the three companies, with twenty-eight participants in total. The influence or level of seniority in their respective firms has little effect on how the interviews were conducted or how much credence would be given to their opinions over others. It is important to show that these organisational actors' opinions were not sought to support or oppose a particular line of thought on alcohol in the workplace but to show the richness of the research topic and its originality. Opinions and viewpoints were gathered so they could be compared and contrasted with political and managerial 'official' accounts.

\section{Findings and analysis}

\section{Archaeological phase: Application of Soft Systems Methodology}

Although we employed only certain aspects of SSM, it is important to discuss its origins and explain how it is applied and adapted for this research as an archaeological aid to Foucault's methods. SSM was developed in the late 1960s (Checkland and Scholes 1990; Checkland 1999) and has evolved (Mirijamdotter 1998). It was a response to the inadequacy of so-called 'hard systems' approaches to problem-solving that required a part of human activity (Damenu and Beaumont 2017) and stressed plural rationalities and uncertainty (Rosenhead 2001). This paper involves a 'controversial' substance like alcohol and aims to understand how it is perceived in the British workplace regarding employee wellbeing. We consider adopting SSM for this phase of the study to enhance understanding of the topic's 'problematic' and 'pluralistic' nature. Because SSM and Foucault's methods make such different assumptions about situations, the notion is that rather than allowing them to fight for supremacy in this paper, they may be utilised in a complementary way to address the many scenarios for which each method is most suited.

In terms of the traditional modes of implementing SSM, this paper differs from Mode 1 and Mode 2 originally proposed by Checkland for its application. The former is linked to the use of systems ideas and the application of the Seven Stage Model in the examination of some aspect of the real world (intervention); the latter is related to reflections on the daily flux of events and ideas using the methodology as a foundation for reflection (interaction) (Holguin 2007). As a result, SSM is utilised to make sense of the information or to learn about this everyday experience (Jackson 2000). The selective and innovative use 
of SSM produces 'archaeological' material that is vital for the process of addressing the research questions.

The use of SSM in this research is strictly limited to organising information involving various appreciations regarding alcohol and its use or misuse in the UK workplace. Although only the first three stages of SSM were used to address the 'archaeological' phase of the research, we have ensured that the main ideas behind its application are organising the diverse views of the stakeholders involved in the problem-situation have been maintained.

As Fig. 1 above presents, there are seven stages of SSM conventionally. However, it was not necessarily designed to be followed sequentially because its processes were extracted from an iterative process. Depending on the problem involved, there can be a backward and forward movement between stages. For the 'problem' discussed in this paper, we only used Stages 1-3. The first two stages involve analysis of the problem-situation and structuring it. At this explanation phase, we were seeking the richest possible "panorama", not of the problem, but of the real situation in which it is found. "Rich Picture" is used to facilitate the process of negotiation (Simon et al. 2016), entails a 'drawing' that depicts the different stakeholders' viewpoints, ranging from issues, conflicts and difficulties. The third stage involves describing the appropriate and relevant systems that have been introduced as the primary definition (Checkland and Scholes 1990).

The use of the initial stages of SSM helps to fulfil Foucault's ideas regarding identifying 'discourses' about a particular situation without judging or making any inferences from it. It is essential to acknowledge that SSM cannot fully tackle the research questions posed since it ignores how discourses are produced about "the disciplines or arguments supporting one or another worldview; nor does SSM inform us how certain worldviews prevail over others" (Holguin 2007, p. 124). Nonetheless, the use of SSM presented here shows an innovative application. It is possible to achieve an initial way of organising information by utilising only three stages of the methodology while adhering to its primary principles about the inclusion and identification of divergent worldviews. The varied use of SSM might be attributed to the fact that the methodology is, after all, designed to be a flexible method (Checkland 2000), and Checkland and Scholes (1990) argue that serious users of the methodology use its stages flexibly rather than sequentially to tackle its limitations. Furthermore, the root definitions are equated to the notion of 'discourses' in the context of this research, primarily because they represent 'what is said' about alcohol in the workplace and consequently adhere to Foucault's emphasis on identifying discourses about a particular situation yet without judging or interpreting it to accomplish the 'archaeology' phase.

Initial critiques of SSM focused on its purported political neutrality regarding Checkland's argument that it does not serve any specific group or class (Flood and Jackson 1991). This criticism, first advanced by Thomas and Lockett (1979), showed how power relations shape how problems are approached. In other words, the structure of 'problems' is governed by power dynamics that are not entirely neutral. Jackson (1985) further argued that soft approaches could not be applied neutrally in situations where economic and social systems create coercive restrictions. Hence, the SSM cannot address the research questions since it makes no reference to how such discourses are produced in terms of the disciplines or arguments that support one or another worldview; nor does it explain why some worldviews prevail over others. While SSM considers the perspectives of various stakeholders, it has also been criticised for lacking a mechanism for questioning the status quo (Jackson 1982; Mingers and Taylor 1992). To this end, Mingers and Taylor (1992) recommended that critical methodologies that explicitly acknowledge power should be created. 


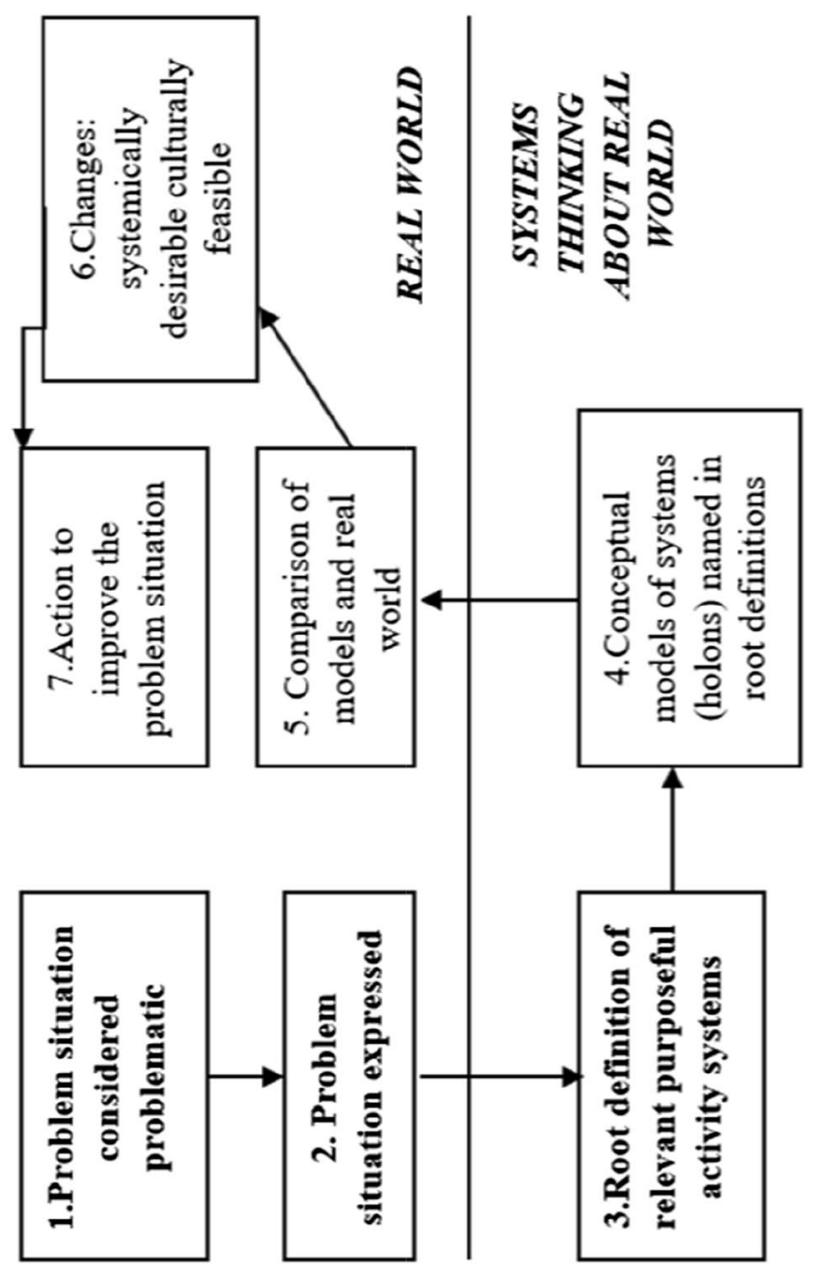

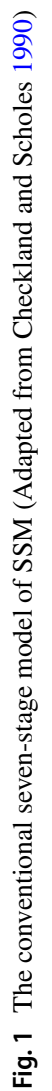




\section{Findings and Analysis}

It is important to note that the views expressed in the 'rich picture' formulation serve as a means of unearthing many aspects of the debate that may not have been given equal exposure as the rest have. A rich picture diagram depicting alcohol in the workplace is indeed challenging to draw, usually formed through various iterations, mainly subjective ones. It is unique to a particular 'problem-situation' but valuable to stimulate debate and understand a problem situation more deeply than achieved in the more conventional analysis (Avison et al. 1992; Bell et al. 2019).

The results suggest that individuals' perceptions, understandings and personal views on alcohol significantly affect how they approach these discussions. Thus, for the individuals interviewed in this research, it was clear that they accepted or rejected alcohol use in the social context within which it was being consumed. In particular, some individuals in these workplaces also accepted or rejected alcohol as a means of resistance or conformity to their various organisational authorities. Knights (2002, p 585) argues that "even in the absence of such threats" from management, "employees work productively and efficiently partly because their identity is tied up in so doing". Such revelations unearth the interplay of power-relations, identities and discourses. However, a criticism that SSM faces is that it fails to take into account power relations and "does not necessarily include reflection on power relationships, nor do the actors necessarily control the analysis practice themselves" (Bednar and Welch 2012, p. 145).

As a result, one may argue that Checkland's SSM approach to power is insufficient to comprehend some of the research's emergent problems, as it is predicated on the openness of discourses and perspectives regarding the problem-situation. The method overlooks the link between discourses or knowledge produced about alcohol in the workplace or how these discourses represent power. Therefore, it is also critical to understand when to stop using a methodology that produces no more answers and, consequently, the benefits of integrating a complementary framework may enhance the aim of the paper. Foucault's approach to power suggests a way around these constraints. He discusses concepts of power and knowledge, as well as the formation of the self, all of which may be relevant in addressing the study questions.

There is a continuous struggle between working for individual interests and the organisation's expectations, especially regarding their wellbeing. As seen in Fig. 2, all viewpoints had an equal platform regardless of who spoke in addressing the problem-situation. Various alcohol perspectives, including moderation, influence the arguments' complexity and depth in the debate. It was uncovered that some organisations that claim to have a zerotolerance policy against drink were seen to support its presence in the workplace.

\section{Relevant systems on alcohol in the workplace}

These varied and broad perspectives on alcohol in the workplace facilitate creating the second stage of SSM, which identifies the relevant systems that lead to a better understanding of the problem situation. At this stage, the research moves from the 'real-world' into the world of systems. This addresses the first research question: What are the relationships between various stakeholders' viewpoints, and how do they shape organisational practice?

Hence, this stage offers a platform for presenting different views and tensions unearthed. It is evident that throughout its history, alcohol has been perceived either on one end as 


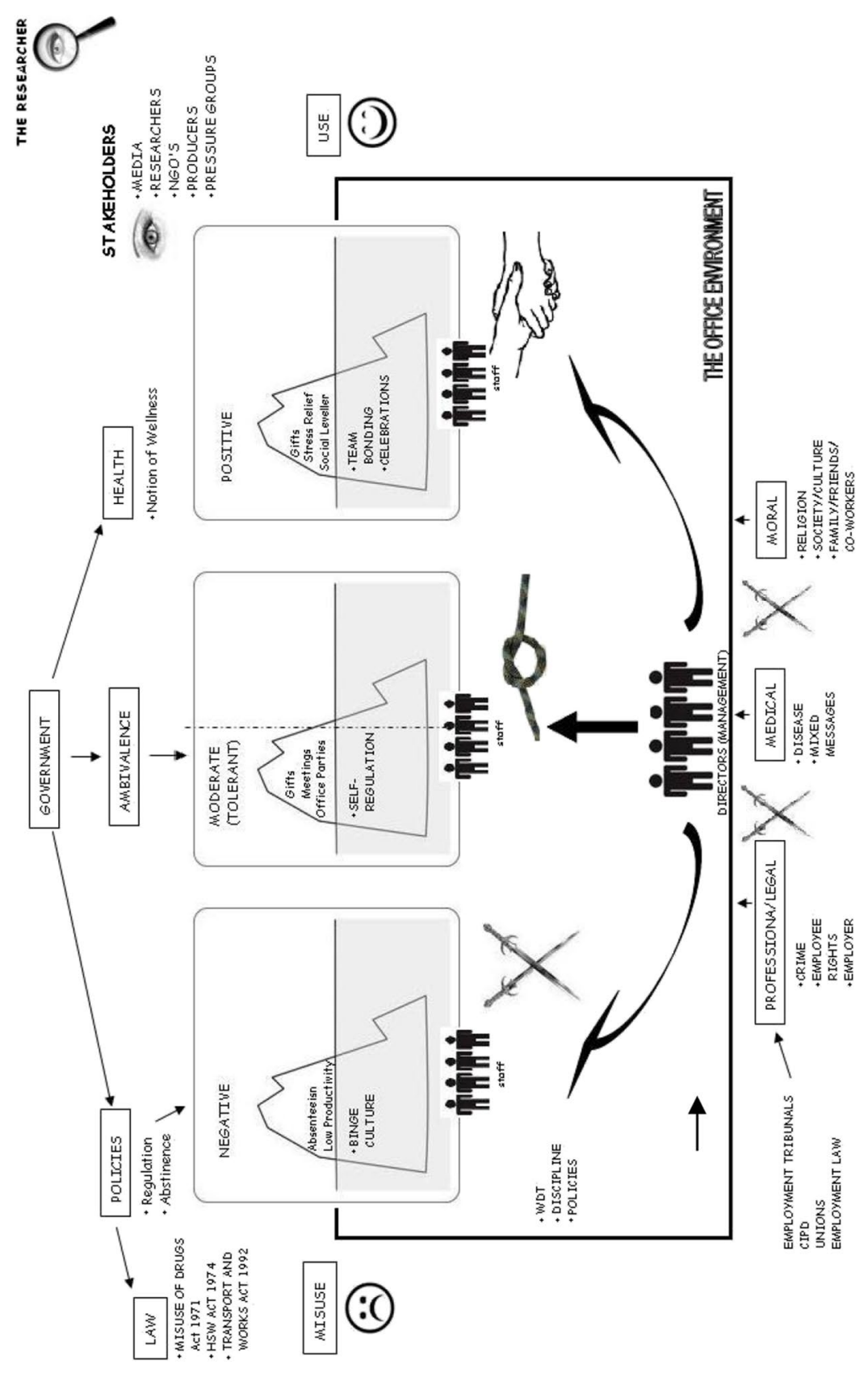

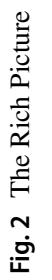


a valuable substance or, on the other hand, a detrimental one to the individual (Ghodse, 2016; Godfrey and Parrot, 2016). However, we might argue that all the views, approaches and understandings of alcohol in the workplace might have been influenced by the broader societal perception of the substance at this particular point in history (Zagenczyk et al. 2008).

\section{Root definitions}

The third stage of SSM involves constructing root definitions, as presented in Table 1, based on the relevant systems identified. The focus here is to show an in-depth understanding of the various discourses that pertains to alcohol in the UK office-based environments. Dufuor (2007) argued that the dichotomous view that alcohol is either only beneficial or only harmful is just too simplistic and one-dimensional; hence, we used root definitions, which involves an assessment of the net outcome and make clear the whole nature of the system in question, to provide an in-depth insight into the issue. Two key major themes were addressed and uncovered.

\section{Positive employee and organisational wellbeing}

Alcohol plays an important role in most social activities, from a business lunch to the parties to the special functions in the workplace such as gift-giving when there is a promotion or other forms of celebration (Pringle 1995; Goldman et al. 1999; Heath 2000). From this perspective, "the use of alcohol is seen as a social cement which along with other group activities binds together the members of the community thereby enhancing group solidarity" (Hunt 1990, pp. 243-244).

The effect of alcohol or its relation to the workplace's internal functioning is often overlooked in most studies since most research literature focuses on the dangers rather than its potential benefits. Nonetheless, employees' alcohol use is often expressed as a direct or unintended response to the physical or psychosocial qualities of the workplace (Frone 2016). The patterns of drinking in the workplace can be described as products of routine or tradition rather than deviance (Ames and Janes 1990), and Clark (1991) adds that individual drinking patterns or reasons for drinking vary even though these variations likely reflect salient group customs.

Factors such as coping with job alienation and stressful job experiences are likely to influence an individual's view of alcohol use in the workplace as having positive effects on their wellbeing and, consequently, their work experience and performance. Some participants stated that drinking alcohol at work served as a coping tool among colleagues (Mackey and Perrewé 2017). One participant highlighted its medicinal value:

Other times if somebody else you are working with is stressing out and they are going through a bad patch, it's quite common for somebody to put an arm around them and say, 'come on, we will go and have a drink' and take them out for a pint. So it is almost used in medicinal terms to relax.

One participant also stated:

Well, it's acceptable but with limits. Everything is acceptable if you know your limits. If you drink one or two glasses of wine to unwind, then you possibly go to work 


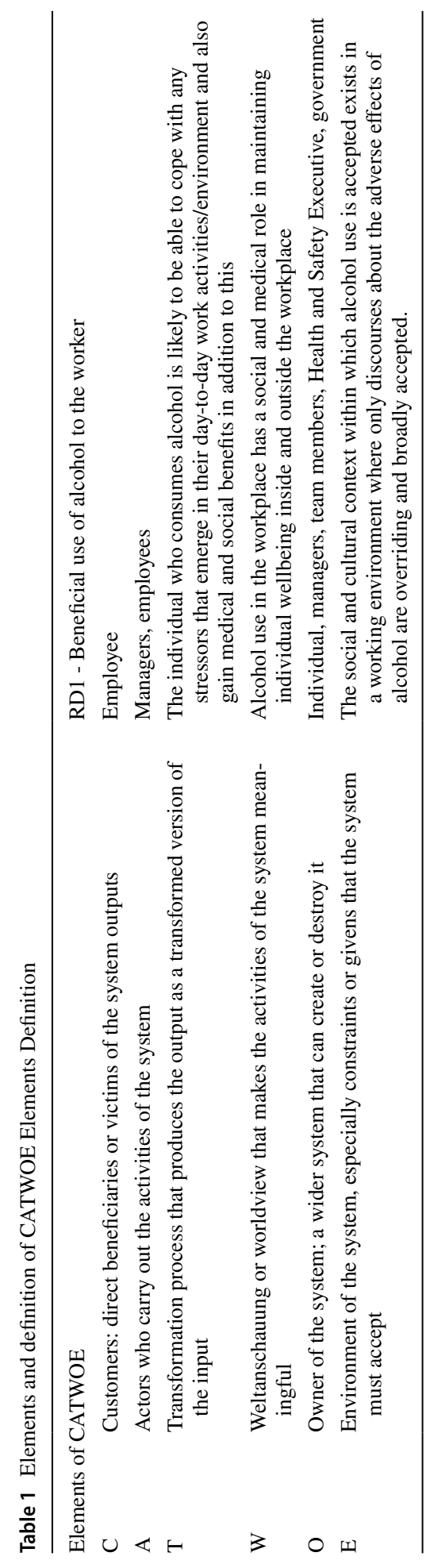


the next day with a fresher attitude and drive. But obviously, if you are going to drink till 6 am when your shift is at 7am, then it's just common sense.

It is possible to portray views that perceive a positive or beneficial effect of alcohol on the individual's overall wellbeing and performance in the workplace, and this is summed up accordingly using the following root definition:

Tolerable views or perceptions regarding alcohol use in the workplace as a result of the perceived health and social benefits of alcohol consumption on the individual (worker) may be justified by subjective health perceptions, medical expertise and cultural contexts, as well as a tool to cope with stress in the modern-day office-based workplace.

Therefore, the above root definition may further be represented as follows in Table 1 below, and root definitions are compiled by assembling CATWOE elements (Mingers et al. 2009).

All three organisations involved in this research had workplace alcohol policies that were either justified by medical, physiological or psychological wellbeing discourses. Hence, these workplaces pursue a 'wellbeing' agenda that aims to produce a healthy and productive employee. Likewise, at the firm level, there have been economic and political discourses to support various techniques and mechanisms that they manage to tackle alcohol (Ghodse 2016). In some sense, when dealing with alcohol, which is consumed as a matter of individual choice, management's authority is legitimised by the backing of discourses from either the medical or academic disciplines whom Sargent (1979) term as the 'helping professions'.

The issue of alcohol in the workplace gets more complicated once it becomes obvious that the discourses surrounding its use in the workplace vary enormously. Here the view is that alcohol positively contributes to the social functioning and relationships with clients and employees and a range of symbolic functions. However, because management is part of formulating or interpreting techniques to address alcohol, the manager becomes an 'expert' and determines when alcohol positively impacts employee wellbeing. Foucault (1982) argues that such expertise and disciplinary knowledge of the management create divisiveness, in which employees are distinguished from one another as 'good' from the 'bad', the normal from the abnormal, criminal from the law-abiding, or sick from the healthy and this consequently produces resistance (Knights 2002, p. 581).

With the manager regarded as the workplace expert, their role is a struggle between power relations and the social arrangements present in the workplace. The interpretation of who is in breach of the alcohol policy lies in the eye of the 'expert' who subjectively interprets it. Often this is done in favour of the organisational wellbeing rather than in the employees' wellbeing. In other words, although management's justification for implementing a workplace alcohol policy is to improve organisational efficiency and maintain a healthy and safe working environment for their workforce, they do not provide any justification for allowing its use in some instances during work-related events.

The practicalities of establishing measures and techniques in addressing alcohol while trying to utilise it in some form for organisational benefits renders alcohol in the workplace very contentious and leaves the employee in a very conflicting predicament. On the one side, the employee is supposed to follow any law in his or her workplace, whereas on the other hand, the same workplace, and especially the "rule-maker", can be a party to specific rules being violated. For instance, the individual is branded as a 'deviant' if he or she reports to work with an alcohol-related hangover, whereas that same individual may be 
offered free drinks, courtesy of management, during an office party sometimes staged during office hours and on office premises. Such conflicting practices and messages, mainly originating from management, place the workforce at the centre of competing discourses about alcohol use and renders the individual worker subject to management's mercy regarding their relationship with alcohol.

Although the benefits that an individual, team or organisation may gain from alcohol consumption have been discussed in this section, the most dominant views or perspectives regarding alcohol in the workplace have been those which have regarded or highlighted the negative impacts of the substance on both the workplace and the individual.

\section{The detrimental impact of alcohol on workers' wellbeing}

For individuals working in office-based environments and specifically in Knowledge-Intensive Firms (KIFs), some views cite that alcohol consumption, especially excessive or heavy drinking, may cause cognitive impairment, affecting the individual's judgement, memory and reaction time. In extreme cases, it is believed that alcohol-related brain damage can affect short-term memory and reduce the ability to engage in abstract thinking or learn new information (White 2003). Alcohol 'misuse' has been reported to harm people other than the drinker, and can have negative consequences for the workplace as a whole since it is typically believed to play a role in decreased worker productivity, increased unintentional injuries, aggression and violence against others (Gmel and Rehm 2003).

In contemporary organisations like KIFs, similar to those recruited in this research, where tasks require problem-solving skills or are complex, alcohol's effect on a person's thought processes and motor skills is more significant (Nicholas and Allsop 1996). While discussing alcohol in an office-based environment, an interviewee argued that:

It's not a good idea no matter what you do. No matter what your workplace is because it's detrimental to your job as a whole. Your work suffers, your view suffers, and the quality of your work suffers.

Several participants echoed this view. A manager in one of the firms stated:

I have done a variety of job roles from administration, labouring, envelope stuffing. I don't think there is particularly a job where I have had a drink at lunch and thought alcohol would help; it always hinders because you are 'knackered' after a couple of hours after drinking and you are ready for home, there is nothing I have done that it has given me a boost for.

Thus, concerning a root definition, these views can be represented as follows:

Views that perceive alcohol as a harmful substance to the employee and, consequently, the work environment due to its physical and social impact on the former and the resulting economic impact on the latter, although studies have mentioned the potential medical and social benefits of alcohol use to the worker.

It is also possible to show the root definition and the transformation that takes place in Table 2 below:

It is important to note that most discourses surrounding alcohol in the workplace have generally been justified by the work of those regarded as experts. The role of management in KIFs is to maintain a productive and harmonious environment. The manager's 'assumed' knowledge about alcohol and its consequences on the organisation legitimise his or her 
role as the expert in making decisions about the workforce's drinking habits. While certain employees disagreed with the alcohol policy in the workplace, none of the participants disagreed with the reasons provided by their respective managements for its enforcement. The majority of participants stated that management would be justified if they punished someone whose work or function in the workplace had suffered due to alcohol consumption. However, such viewpoints still hand the privilege of interpretation to the individuals in management, paying little heed to the individual employee's personal lives and attitudes towards drinking and whether alcohol use might impair their work function and wellbeing.

It is clear that when discussing the topic of alcohol in the workplace, only one group, that is, the management, tend to have a dominant voice. Hence although alcohol consumption in the UK is commonplace, drinking in the office environment is not acceptable and rather discriminated against, especially if consumed by employees without the management's authorisation. Such views towards alcohol consumption in the workplace make the 'drinker' subject to many forms of control and techniques and exposes the employee to potential disciplinary action and control measures, if deemed to contravene the rules.

In the face of such contradictory regimes and practices, it is evident that some of the actions taken by management aim to instil into the individual worker a form of identity that accepts and obeys management's rules and practices. This means that the management's views were in contrast to some employees' construction of their organisational realities and identities, with the latter having to reject their own notions of wellbeing to fit into the organisation's expectations. The notion of such contrasts offers a helpful way to understand the relationship between discourse and identity and the role of organisational wellbeing initiatives to manipulate the employee's identities, regardless of the latter's worldviews. From offering Employee Assistance Programs (EAPs) to problem-drinkers to utilising alcohol as an incentive for outstanding success, management has often sought to establish an illusion that their inconsistent actions around alcohol help both the organisation and employee wellbeing.

Hence, "by reconstituting the individual's understanding of him/herself in line with the requirements (or norms) of the organisation, e.g. as productive, proactive and reflective, the aim is to instil a form of self-discipline in the subject" (Hodgson 2000, p. 242). The relevance of identity, in this case, is the possibility it gives management and the organisation as a whole. That is, for the continuous functioning of such techniques and mechanisms of control since the worker is "encouraged to monitor his/herself with regards to norms which are now central to their notion of self"; in effect, "by incorporating in the subjects

Table 2 RD2 - Detrimental Impacts of Alcohol on the Worker

\section{Elements Definition}

C Employee, co-workers, managers, the organisation

A Managers, employees

$\mathrm{T} \quad$ The individual consuming alcohol in the workplace becomes inefficient, and his or her work performance is negatively impacted

W Alcohol negatively affects the workplace due to its detrimental impact on the individual's wellbeing.

O Employees, managers, team members, healthcare professionals, government

E The social context in which alcohol is used in the workplace exists in a broader debate in which discourses about the harmful effects of alcohol are dominant and widely accepted. 
the responsibility for monitoring and correcting behaviour is shifted to the subject him/ herself" (Hodgson 2000, p. 242).

The paradox here is that, at times, the application of these modes of regulation is constructed and performed by the subject as confirmation of their autonomy and freedom from management's control. In this regard, some employees fail to recognise that their abstinence from alcohol the night before a working day, to ensure a productive day in the office, may result from the self-discipline inculcated in them their superiors for their wellbeing. This form of self-disciplinary control represents a deep level of internalisation of this construction of identity. The organisational and individual wellbeing discourses present in the workplace makes all aspects of the employees' working and private lives visible all the time.

Consequently, the employees are always under the gaze of the manager via workplace health programmes and wellbeing initiatives. This parallels what Foucault (1977) refers to as the 'panopticon,' in which inmates who felt continuously watched began to self-discipline. "In making the employees' lives outside the workplace visible", some particular workplace discourses force "employees to discipline themselves in the name of health both inside and outside work", especially in terms of their drinking patterns (Allender et al. 2006, p. 87).

\section{Discussion}

By combining SSM and Foucault's ideas throughout the paper and consequently focusing on the notion of discourses, which is adequately addressed by the use of SSM, we have identified, classified and contrasted different discourses, practices, and organisational actors to examine the interaction between the organisational discourses and the actual organisational practices regarding alcohol in the workplace. Nonetheless, at the core of these discourses lie the individual worker who is expected or 'forced' to manoeuvre his or her way amongst a mixture of discourses on alcohol and wellbeing that eventually shape them into the 'ideal' employee. Hence, the operation of the regimes of power/knowledge and the surrounding discourses that render the modern individual a subject lies at the heart of the discussion. While debating and studying alcohol in the workplace in this paper, it has been revealed that the worker becomes subjectified through the operation of power; that is to say that:

"For Foucault, power operates on individuals in two ways. It objectivises them through making them objects of knowledge - that is, they become subjectified. They are presented with an image of themselves, an identity, which then becomes the basis of their self-knowledge. Both provide the basis for individuals to modify and change their behaviour."

Furthermore, Townley (1998, p. 199) adds that a Foucauldian analysis offers a reminder:

"that the individual is a product of power, irreducible to an internal core of meaning, continuously constituted and constructed...certain bodies, certain gestures, certain discourses, certain desires come to be constituted as individuals. The individual...is I believe one of [power's] prime effects".

In the workplace, the topic of alcohol serves as a means and technique for management to transform the individual's subjectivity to correspond to the organisation's goals. In other words, by acting as 'experts' with relevant knowledge on the substance and exercising 
different forms of control through regulating, dictating and providing advice on alcohol in the workplace, the management of these contemporary work organisations "provide a 'truth' and inscribe these 'truths' on the subjectivity of the individual" (Hodgson 2000, p. 25). As a consequence, the method of selecting and adopting organisational alcohol policy or health programmes is made likely by the transformation or modification of a worker's self-understanding through the interaction of power relationships and managerial knowledge and practices (Valero-Silva 1999; Knight 2002).

In reflection, this paper has made the workplace processes of subjectification more visible and drawn attention to the complex interplay between technologies of power and technologies of the self (Foucault 1977). For instance, it is possible to draw themes throughout this paper that connects organisational and management discourses on alcohol and employee wellbeing, the political and economic objectives for more productive workers, the actual workplace practices, and the modern construction of the 'ideal worker' subject as a natural way of 'being' at work (Harman 2007). In other words, this points to a heterogeneous network consisting of the state, organisational health and wellbeing 'experts', researchers and workplace managers that produce a 'regime of truth' of autonomous subjectivity in the workplace through alcohol. However, Foucault stresses throughout his works the importance of the notions of power/knowledge, challenging the human sciences' claim of objectivity by disclosing their reliance on power to construct 'truths' as well as the power effects of these 'truths' (Hodgson 2000). Foucault declares that "all sciences, analyses and practices employing the root "psycho-"' have a central role in the procedures of individualisation of the individual subject and do so by "thus substituting for the individuality of the memorable man that of the calculable man" (Foucault 1977, p. 193).

Bell and Taylor (2003) note that actions by management and organisations relating to alcohol use in the workplace can also be connected with what Foucault calls 'pastoral' power. Harman (2007, p. 26) adds that "using the technology of the confession, pastoral power individualises through enabling 'the truth' to be spoken about our utmost thoughts and feelings". In other words, the use of pastoral power in contemporary society by the state or governing bodies had permitted power to extend into "the very grains of individuals" and "touches their bodies and inserts itself into their actions and attitudes, their discourses, learning practices and everyday lives" (Foucault 1980, p. 39). For example, as with alcohol in the workplace, pastoral power may be said to have spread in contemporary organisations through 'experts' such as healthcare professionals and management. Moreover, the very notion of wellbeing being propagated in these organisations is described by Sointu (2005) as being produced in and through broader social perceptions and practices and subject to more sweeping societal changes in subjectivity. Hence this mode of power is described by Foucault as follows:

"This form of power applies itself to immediate everyday life which categorises the individual, marks him by his own individuality, attaches him to his own identity, imposes a law of truth on him which he must recognise and which others have to recognise in him. It is a form of power which makes individuals subjects" (Foucault 1982, p. 781).

Therefore, as has been revealed in this research with regards to the topic of alcohol in the workplace, it is evident that "the diverse forms of normalisation and control exercised in the workplace can be seen to draw on power/knowledge regimes to discipline the employee and ensure his/her productive conduct" (Hodgson 2000, p. 253). As with Rose (1990)'s work on the enquiry into the production of the human subject, he stresses that in 
the production of the 'productive subject', the forms of surveillance and control developed by management can be seen as a technology for reforming workers as 'productive subjects'.

It is important to note that the legal implications of alcohol use or its misuse to the organisation are not a straightforward issue (IIDTW 2004), there is no direct legislation, and vital legal questions hinge on the interpretation of a range of provisions in health and safety, employment, human rights and data protection law. The organisation's role in the discussion about alcohol in the workplace should also be acknowledged not just for the consequences that they might face but also for the part that they may play in perpetuating this phenomenon.

\section{Conclusion}

The paper illustrated how Foucault's method of analysis contributes to comprehending the complexities and conflicts that exist in organisational practices and viewpoints relating to alcohol and the different philosophies that shape them. In addressing the questions set out, the focus was placed on how alcohol is utilised to shape the employee's subjectivity and behaviour concerning their wellbeing. The paper explored power relations and the relationships between power relations. The revelations from the analysed data have contributed to a better understanding of the nuances in the discourses that shape the debate around alcohol in the UK workplace, making it a legitimate concern in the UK regarding employee wellbeing. This was achieved by going beyond the documents and statements accessible in the public sphere and abandoning the traditional "managerial and hierarchical" approach that focuses on what the experts/managers have to say over other organisational stakeholders.

The increasing role of the employer or management in the debate is evident from the discussion. For instance, it is worth noting that, in some situations, alcohol may be viewed to play a beneficial role in the workplace, both as a supposed antidote to the stresses of the contemporary workplace and as a means of socialising or networking with clients and colleagues. The plurality of discourses and their respective origins has established the authority of some discourses over others. It is clear from the interviews that certain people came to support the opinions of the 'experts', not that they identified with them. They instead had internalised the discourses circulated by management about alcohol and internalised them as 'truths'. These discourses have undeniably created the circumstances for the 'normalisation' of the substance. Thus, they come to understand their identity in terms of this 'truth'.

The views that may portray alcohol in a negative light in the workplace and ones which may fall in line with official 'managerial' discourses, this 'truth' eventually serves as a form of self-discipline; which the individual utilises to shape his or her actions in line with the accepted norms. As with Foucault's ideas, this research has not looked at power as a commodity held or possessed or as something embodied in an individual, institution, or structure or as something to be used for organisational or individual purposes. On the other hand, this research has aimed to explore more deeply power relations, and how mechanisms of power affect everyday lives, in this case, the individuals' everyday lives in the organisation.

Finally, the successful use of SSM as an aid to Foucault's method of analysis represents a significant contribution of this paper. The use of SSM was crucial in organising certain aspects of the literature and interview data used in the research's archaeological stage. By integrating the methodologies, the research has offered a more holistic explanation with data examined from excluded voices. Furthermore, when power issues arise when 
we examine alcohol and wellbeing in the UK workplace through Foucault's lens to social phenomena, and although SSM fails to identify or acknowledge these, it does not understate or downplay its effective contribution to the topic.

Data availability The original datasets generated during and/or analysed during this study are available from the corresponding author on request.

\section{Declarations}

Conflict of interest The authors have no relevant financial or non-financial interests to disclose. The authors have no competing interests to declare that are relevant to the content of this paper. All authors certify that they have no affiliations with or involvement in any organisation or entity with any financial interest or non-financial interest in the subject matter or materials discussed in this manuscript. The authors have no financial or proprietary interests in any material discussed in this article.

Open Access This article is licensed under a Creative Commons Attribution 4.0 International License, which permits use, sharing, adaptation, distribution and reproduction in any medium or format, as long as you give appropriate credit to the original author(s) and the source, provide a link to the Creative Commons licence, and indicate if changes were made. The images or other third party material in this article are included in the article's Creative Commons licence, unless indicated otherwise in a credit line to the material. If material is not included in the article's Creative Commons licence and your intended use is not permitted by statutory regulation or exceeds the permitted use, you will need to obtain permission directly from the copyright holder. To view a copy of this licence, visit http://creativecommons.org/licenses/by/4.0/.

\section{References}

Ackermann F, Franco LA, Rouwette E, White L (2014) Special issue on problem structuring research and practice. Euro Journal on Decision Processes 2(3/4):165-172

Allender S, Colquhoun D, Kelly P (2006) Competing discourses of workplace health. Health 10(1):75-93

Allsop S, Pidd K (2001) The nature of drug-related harm in the workplace. In: Allsop S, Phillips M, Calogero C (eds) Drug and Work: Responding to Alcohol and other Drug Problems in Australian Workplaces. Melbourne, IP Communications, pp 5-19.

Ames G, Grube JW (1999) Alcohol availability and workplace drinking: mixed-method analysis. Journal of Alcohol Studies 60(3):383-393

Ames GM, Janes C (1990) Drinking, social networks, and the workplace: results of an environmentally focused study. In: Roman P (ed) Alcohol Problem Prevention in the Workplace. Quorum Books, New York, pp 95-112

Aquino MGD (2019) Notions of subject and power in Foucaultian readings and their influence in organisation and people management studies. Cadernos EBAPE.BR 17(3):448-459

Avison DE, Golder PA, Shah HU (1992) Towards an SSM toolkit: rich picture diagramming. European Journal of Information Systems 1(6):397-407

Banta WF, Tennant F (1989) Complete handbook for combating substance abuse in the workplace. Lexington, Lexington Books

Bednar P, Welch C (2012) Critical systemic thinking as a foundation for information systems research practice. Journal of Information, Communication \& Ethics in Society 10(3):144-155

Bell E, Taylor S (2003) The elevation of work: pastoral power and the new age work ethic. Organisation 10(2):329-349

Bell S, Berg T, Morse S (2019) Towards an Understanding of Rich Picture Interpretation. Systemic Practice and Action Research 32:601-614. https://doi.org/10.1007/s11213-018-9476-5

Bhattacharya A (2019) Financial headache: the cost of workplace hangovers and intoxications to the UK economy. June. London, Institute of Alcohol Studies Publication.

Burawoy M (1985) Politics of Production: Factory Regimes Under Capitalism and Socialism. Verso, London 
Burton R, Henn C, Lavoie D, Wolff A, Marsden J, Sheron N (2016) The Public Health Burden of Alcohol and the Effectiveness and Cost-Effectiveness of Alcohol Control Policies. An Evidence Review. Public Health England Publications.

Checkland PB (1999) Soft Systems Methodology: A 30-Year Retrospective. John Wiley and Sons, Chichester

Checkland PB (2000) Soft systems methodology: a thirty-year retrospective. Systems Research and Behavioral Science 17:S11-S58

Checkland PB, Scholes J (1990) Soft Systems Methodology in Action. John Wiley and Sons, Chichester

CIPD (2020) Managing Drug and Alcohol Misuse at Work. Chartered Institute of Personnel and Development, London

Clark WB (1991) Introduction to drinking contexts. In: Clark WB, Hilton ME (eds) Alcohol in America: Drinking Practices and Problems. SUNY Press, Albany, pp 249-256

Damenu TK, Beaumont C (2017) Analysing information security in a bank using soft systems methodology. Information and Computer Security 25(3):240-258

de Graff R, Tuithof M, van Dorsselaer S, ten Have M (2012) Comparing the effects on work performance of mental and physical disorders. Social Psychiatry and Psychiatric Epidemiology 47(11):1873-1883

Deetz S (1998) Discursive formations, strategised, subordination and self-surveillance. In: McKinlay A, Starkey K (eds) Foucault, Management and Organisation Theory. Sage Publications Ltd, London, pp 151-172

Dufour MC (2007) Risks and benefits of alcohol use over the life span. Alcohol Health and Research World 20(3):141-151

Duquemin H, Rabaiotti G, Tomlinson I, Stevens M (2019) Services Sector, UK: 2008 to 2018. Office of National Statistics.

Flood R and Jackson MC (1991) Critical Systems Thinking: Directed Readings (Eds.). Chichester: John Wiley and Sons.

Foucault M (1977) Discipline and Punish: The Birth of the Prison. Allen, London

Foucault M (1980) Power/Knowledge: Selected Interviews and Other Writings 1972 - 1977. C Gordon (ed). New York: Pantheon.

Foucault M (1982) The subject and power. Critical Inquiry 8(4):777-795

Foucault M (1984/1986) The Care of the Self (R. Hurley, Trans.). New York: Vintage. Lane/Penguin Press.

Foucault M (1985) History of Sexuality, Vol. II: The Use of Pleasure. New York: Pantheon.

Foucault M (1988) Technologies of Self. In: Martin L, Gutman H, Hutton P (eds) Technologies of the Self. University of Massachusetts Press, Amherst, pp 16-49

French MT, Maclean JC, Sindelar JL, Fang H (2011) The morning after: Alcohol misuse and employment problems. Applied Economics 43(21):2705-2720

Frone MR (2013) Alcohol and Illicit Drug Use in the Workforce and Workplace. American Psychological Association, Washington DC

Frone MR (2015) Relations of negative and positive work experiences to employee alcohol use: Testing the intervening role of negative and positive work rumination. Journal of Occupational Health Psychology 20:148-160

Frone MR (2016) Work stress and alcohol use: Developing and testing a biphasic self-medication model. Work and Stress 30:374-394

Galea S, Ghodse H (2016) Drug misuse and the work culture. In: Ghodse H (ed) Addiction at Work: Tackling Drug Use and Misuse in the Workplace. Routledge, London, pp 33-40

Geertz C (1983) Local Knowledge. Basic Books, New York

Ghodse H (2016) Drugs and alcohol in the workplace. In: Ghodse H (ed) Addiction at Work: Tackling Drug Use and Misuse in the Workplace. Routledge, London, pp 1-9

Gill J (1994) Alcohol problems in employment: epidemiology and responses. Alcohol and Alcoholism 29(3):233-248

Gmel G, Rehm J (2003) Harmful alcohol use. Alcohol Research and Health 27(1):52-62

Godfrey C, Parrot S (2016) Extent of the problem and cost to the employer. In: Ghodse H (ed) Addiction at Work: Tackling Drug Use and Misuse in the Workplace. Routledge, London, pp 21-32

Goldman MS, Del Boca FK, Darkes J (1999) Alcohol expectancy theory: The application of cognitive neuroscience. In: KE Leonard and HT Blane (eds) The Guilford Substance Abuse Series. Psychological Theories of Drinking and Alcoholism. New York: The Guilford Press, pp. 203-246.

Harman K (2007) Re-thinking workplace learning: worker subjectivity/ies as sites of alignments and resistance. $\mathrm{PhD}$ Thesis, University of Technology, Australia.

Heath DB (2000) Drinking Occasions: Comparative Perspectives on Alcohol and Culture. Brunner/Mazel, Philadelphia 
Henderson M, Hutcheson G, Davies J (1996) Alcohol and the workplace. European Series. No. 67, WHO Regional Publications,

Hodgson DE (2000) Discourse, Discipline and the Subject: A Foucauldian Analysis of the UK Financial Services Industry. Aldershot: Ashgate.

Holguin BA (2007) Understanding the cannabis reclassification in the United Kingdom 2002-04. PhD Thesis, University of Hull, UK.

Hunt GP (1990) The anthropology of drinking: a case of cohesion without division. Alcologia 2:243-247

Independent Inquiry into Drug Testing at Work IIDTW (2004) Drug testing in the workplace: the report of the independent inquiry into drug testing at work. Joseph Rowntree Foundation, York

Jackson MC (1982) The nature of 'soft' systems thinking: the work of Churchman, Ackoff and Checkland. Journal of Applied Systems Analysis 9:17-29

Jackson MC (1985) Social systems theory and practice: the need for a critical approach. International Journal of General Systems 10:135-151

Jackson MC (2000) Systems Approaches to Management. Kluwer Academic/Plenum Publishers, New York

Kinghts D (2002) Writing organisational analysis into Foucault. Organisation 9:575-593.

Ling J, Smith KE, Wilson GB, Brierley-Jones L, Crosland A, Kaner EF, Haighton CA (2012) The 'other' in patterns of drinking: A qualitative study of attitudes towards alcohol use among professional, managerial and clerical workers. BMC public health 12(1):892

Lucas G (2016) Effects and risks of workplace culture. In: Ghodse H (ed) Addiction at Work: Tackling Drug Use and Misuse in the Workplace. Routledge, London, pp 109-126

Mackey JD, Perrewé PL (2017) The relationships between hindrance stressors, problem drinking, and somatic complaints at work. Group and Organization Management 44(4):1-32

McQueen JM, Ballinger C, Howe TE (2017) Factors associated with alcohol reduction in harmful and hazardous drinkers following alcohol brief intervention in Scotland: A qualitative enquiry. BMC Health Service Research 17(1):181

Midford R (2001) The nature and extent of drug-related harm in the workplace. In: S Allsop, M Phillips and Calogero C (eds) Drug and Work: Responding to Alcohol and Other Drug Problems in Australian Workplaces. Melbourne: IP Communications, pp. 42-56.

Mingers J, Taylor S (1992) The use of soft systems methodology in practice. Journal of the Operational Research Society 43(4):321-332

Mingers J, Liu W, Meng W (2009) Using SSM to structure the identification of inputs and outputs in DEA. Journal of the Operational Research Society 60(2):168-179

Mirijamdotter A (1998) A multi-modal systems extension to soft systems methodology. PhD Thesis, Lulea University of Technology, Sweden.

Muhlack E, Carter D, Braunack-Mayer A, Morfidis N, Elliot J (2018) Constructions of alcohol consumption by non-problematised middle-aged drinkers: a qualitative systematic review. BMC Public Health 18(1016).

Munro I (2014) Organisational ethics and Foucault's 'art of living': lessons from social movement organisations. Organisation studies 35(8):1127-1148

Nesvåg S, Duckert F (2017) Work-related drinking and processes of social integration and marginalisation in two Norwegian workplaces. Culture and Organization 23(3):157-176

Nicholas R, Allsop S (1996) Alcohol and Drugs in the Workplace: Issues Trends and Practices. The Chamber of Mines and Energy of West Australia, Perth

Nicholson P, Mayho G, Sharp C (2017) Alcohol, Drugs and the Workplace: The Role of Medical Professionals (2nd ed). BMA.

Parker I (1992) Discourse Dynamics: Critical Analysis for Social and Individual Psychology. Routledge, London

Patton MQ (2002) Qualitative Research and Evaluation Methods, 3rd edn. Sage, Thousand Oaks

Pidd K, Roche A, Cameron J, Lee N, Jenner L, Duraisingam V (2018) Workplace alcohol harm-reduction intervention in Australia: cluster non-randomised controlled trial. Drug and Alcohol Review 37(4): $1-4$

Pringle JK (1995) Managers' alcohol use: roles and symbolic functions. Journal of Business and Psychology 9(4):435-440

Priola V, Lasio D, Serri F, De Simone S (2018) The organisation of sexuality and the sexuality of organisation: A genealogical analysis of sexual 'inclusive exclusion' at work. Organisation 25(6):732-754

Public Health England (2018) Adult substance misuse treatment statistics 2018 to 2019: Report. PHE Publications

PwC (2021) UK Economic Outlook January 2021. PricewaterhouseCooper, London

Raffnsøe S, Gudmand-Høyer M, Thaning MS (2016) Foucault's dispositive: The perspicacity of dispositive analytics in organisational research. Organisation 23(2):272-298 
Robertson M, Swan J (2004) Going public: the emergence and effects of soft bureaucracy within a knowledge-intensive firm. Organisation 11(1):123-148

Roche A, Chapman J, Duraisingam V, Phillips B, Finnane J, Pidd K (2020) Construction workers' alcohol use, knowledge, perceptions of risk and workplace norms. Drug and Alcohol Review 39(7):941-949

Roche A, Kostadinov V, Fischer JA (2017) Stress and addiction. In: Cooper CL, Quick JC (eds) The Handbook of Stress and Health: A Guide to Research and Practice. John Wiley and Sons, Chichester, pp 252-282

Roche A, Kostadinov V, McEntee A, Allan J, Meumann N, McLaughlin L (2019) Evaluation of a workshop to address drugs and alcohol in the workplace. International Journal of Workplace Health Management 12(1):2-14

Rose J (2000) Soft systems methodology as a social science research tool. Systems Research and Behavioral Science 14(4):249-258

Rose N (1990) Governing the Soul: The Shaping of the Private Self. Routledge, London

Rose N (1999) Power of Freedom: Reframing Political Thought. Cambridge University Press, Cambridge

Rosenau P (1992) Postmodernism and the Social Sciences: Insights, Inroads and Intrusions. Princeton University Press, Princeton, NJ

Rosenhead J, Mingers JR (2001) Rational analysis for a problematic world revisited: problem structuring methods for complexity, uncertainty and conflict, 2nd edn. John Wiley and Sons, Chichester

Rumsby R (2009) Development, wellbeing and organisation: perceptions of employees in schools. PhD Thesis, University of Leicester, UK.

Sointu E (2005) The rise of an ideal: changing discourses of wellbeing. The Sociological Review 53(2):255-274

Stowell F (2020) Power in the 'organisation': a soft systems perspective. Syst Pract Action Res 34(5):515535. https://doi.org/10.1007/s11213-020-09541-w

Sullivan T, Edgar F, Mcandrew I (2019) The hidden costs of employee drinking: a quantitative analysis. Drug and Alcohol Review 38(5):543-553

Suri H (2011) Purposeful Sampling in Qualitative Research Synthesis. Qualitative Research Journal 11(2):63-75. https://doi.org/10.3316/QRJ1102063

Taylor C (1994) The politics of recognition. In: A Gutmann (ed) Multiculturalism, Examining the Politics of Recognition. New Jersey: Princeton University Press: 25-73.

Thomas AR and Lockett M (1979) Marxism and systems research: values in practical action. Proceedings of the 23rd Annual Conference of the International Society for General Systems Research, ISGRS 1979

Thompson A, Ashcroft DM, Owens L, van Staa TP, Pirmohamed M (2017) Drug therapy for alcohol dependence in primary care in the UK: a clinical practice research datalink study. PLoS ONE 12(3):e0173272. https://doi.org/10.1371/journal.pone.017327

Townley B (1998) Beyond good and evil: depth and division in the management of human resources. In: McKinlay A, Starkey K (eds) Foucault, Management and Organisation Theory. Sage, London, pp $191-210$

TUC (2019) Drugs and alcohol in the workplace: guidance for workplace representatives. Trades Union Congress, London

Valero-Silva N (1999) A Critical History of the Origins of Critical Systems Thinking. PhD Thesis, University of Hull, UK.

Välikangas A, Seeck H (2011) Exploring the Foucauldian interpretation of power and subject in organisations. Journal of Management and Organization 17(6):812-827

Vaz P, Bruno F (2003) Types of self-surveillance: From abnormality to individuals 'at risk'. Surveillance and Society 1(3):272-291

Watson TJ (2017) Sociology, Work and Organisation, 7th edn. Routledge, London

White AM (2003) What happened? Alcohol, memory blackouts, and the brain. Alcohol Research \& Health 27(2):186-196

Woodhouse J (2020) Alcohol: Minimum pricing. House of Commons Library, Westminister

Yu JE, Hong HC (2009) Systemic design for applying the combined use of SSM and CDA to social practices. Systemic Practice and Action Research 29:149-171

Zagenczyk TJ, Gibney R, Murrell AJ, Boss SR (2008) Friends don't make friends good citizens, but advisors do. Group and Organization Management 33(6):760-780

Publisher's Note Springer Nature remains neutral with regard to jurisdictional claims in published maps and institutional affiliations. 